\title{
A case of Dystocia due to Fetal Ascites in Murrah Buffalo
}

\author{
Ankit Kumar Ahuja ${ }^{1 *}$, Pooja Dogra ${ }^{2}$, Shivkumar ${ }^{3}$, Shahbaz Singh Dhindsa ${ }^{4}$, Harpreet Singh $^{5}$ \\ 1,2,3,5 Department of Veterinary Gynecology and Obstetrics, Guru Angad Dev Veterinary and Animal Sciences University, \\ Ludhiana, Punjab, India \\ ${ }^{4}$ Department of Animal Genetics and Breeding, College of Veterinary Science, Guru Angad Dev Veterinary and Animal Sciences \\ University, Ludhiana, Punjab, India
}

\begin{abstract}
Dystocia in buffalo due to fetal causes is not common. However there are reports suggesting dystocia due to dropsical condition of fetus. Present case reports one of the fetal dropsical conditions in buffalo. In this case we report a successful management of dystocia due to fetal ascites in Murrah buffalo by incising the fetal abdomen to take out the fluid from peritoneum.
\end{abstract}

Keywords-Fetal Ascites, dystocia, insufficient drainage.

\section{INTRODUCTION}

Chances of dystocia in buffaloes are less when compared to cattle due more voluminous pelvis. Fetomaternal disproportion and faulty disposition of fetus has been reported as commonest causes of dystocia in buffalo. Dystocia can also occur due to dropsical condition of fetus like hydrocephalus, ascites, hydrothorax and anasarca(Purohit et al., 2006; Purohit et al., 2012). However, the report of fetal ascites as a cause of dystocia in buffalo is rare (Luthraet al., 2001).Honparkheet al (2003) and Roberts(2004) reported the association of fetal asciteswith dropsical condition of the uterus, mesotheliomas of the fetal abdomen and brucellosis. Ascites can be caused by overproduction or insufficient drainage of peritoneal fluid and blockage of lymphatics(Sloss and Duffy, 1980). Ascites can alsooccurr due to reduced urinary excretion (Purohitet al., 2012).

\section{CASE HISTORY AND OBSERVATION}

A six year old Murrah buffalo in second parity was presented in GADVASU clinic with the history of complete gestation period. Animal was straining from last night and progressed to second stage but after that no improvement has occurred. Buffalo was alert and active. Per vaginum examination revealed completely relaxed cervix with fetus in anterior longitudinal presentation and dorso sacral position and two forelimbs in birth canal. Thorough examination revealed fetus abdomen filled with fluid suggesting a case of fetal ascites.

\section{TREATMENT}

An epidural anesthesia with $2 \%$ lignocaine is given to the animal to prevent excessive straining. A guided fetotome knife was inserted per vaginum to incise the fetal abdomen. After giving incision about 30 litre of brown colored fluid mixed with blood comes out (Fig 1). Partial fetal repulsion and adjustment of correct parturition posture was done to take out the fetus. Placenta was also taken out by rolling it on the hand. The fetus was comparatively smaller in size and kidneys and liver was showing some degenerative changes.However abnormal drainage or blockage of lymphatics can also aggreviate the problemBuffalo was given Inj. Gentamicin $20 \mathrm{ml}$ I/M o.d. and Inj. Enrofloxacin $20 \mathrm{ml} \mathrm{I} / \mathrm{M}$ o.d. on alternate days for five days, Inj. RL 4 Liter I/V, Inj. Metrogyl 1.5 Liter I/V and Intrauterine bolus Furea was kept.

\section{DISCUSSION}

Arthur et al. (1986) stated that ascites may be due to hepatic lesions, general venous congestion or urinary obstruction with or without rupture of bladder. Placental dysfunction consequent to incompatibility of dam and fetus may predispose to fetal dropsy. Ascetic condition in this case may be due to cystic condition of kidney and rupture of urinary bladder or the overproduction or insufficient drainage of peritoneal fluid. The fetal ascites resulted into dystocia as a result of increase in abdominal diameter. Approaches similar to the present case for vaginal fetal delivery have been recorded in many previous studies (Roberts, 1971; Selvarajuet al., 2009; Ravikumaret al., 2013). It was concluded that ascetic fetus can be delivered by abdominal puncture. The etiology for polycystic kidney was not established yet, however, some etiologies responsible for renal cyst conditions are recognized to be 
related with autosomal recessive genes (Smith et al., 1996), chemicals like corticosteroids (Filmeretal., 1973) and diphenylamine (Thomas et al., 1957). Calves with polycystic kidney may be stillborn with other abnormalities or die shortly after birth without other abnormalities (Jubb and Kennedy, 1993).

\section{REFERENCES}

[1] Arthur, G. H., Noakes, D. E., Pearson, H and Parkinson, T. J. 1996. VeterinaryReproduction and obstetrics. 7th ed., W.B. Saunders Co., Ltd., Philadelphia, pp. 302-307.

[2] Filmer, R.B., Carone, F.A., Rawl, R.G. and Babcock, J.R. 1973. Adrenal corticosteroid induced renal cystic disease in the new born hamster. American Journal of Pathology, 72: 461-472.

[3] Hoparkhe, M, Kumar A and Gandotra VK, 2003. Dystocia due to accumulation of fluid in peritoneal cavity and intestines of fetus in a cross breed cow. Indian Journal of Animal Reproduction 24(1): 83-84.

[4] Jubb, K.V.F. and Kennedy, P.C., 1970. Pathology of domestic animals. Academic Press, NYC Vol. I. 2nd Ed.

[5] Luthra, R.A., Kumar P. and Kumar R. 2001. A rare case of dystocia due to fetal ascites in a buffalo. The Blue CrossBook, 17: 25-27.

[6] Purohit G.N., Gaur M, Sharma A, 2006. Dystocia in Rathi cows due to congenital hydrocephalus. Indian $\mathbf{J}$ AnimReprod 27(1): 98-99.
[7] Purohit G.N., Kumar P., Solanki K., Shekhar C., and Yadav S. P. 2012. Perspectives of fetal dystocia in cattle and buffalo; Vet. Sci. Dev. 2: 8

[8] Ravikumar K, Selvaraju M, Kumaresan A and Sivaraman S, 2013. Dystocia due to fetal ascites in Jersey cross bred cow-A case report. Shanlax International Journal Veterinary science 1: 32-33.

[9] Roberts SJ, 1971. Veterinary Obstetrics and Genital Diseases, 2nd ed. CBS Publishers, New Delhi.

[10] Roberts SJ, 2004. Diagnosis and Treatment of Dystocia. Veterinary obstetrics and Genital Diseases. 2nd Ed. CBS Publishers and Distributor's, p. 283.

[11] Selvaraju M, Ravikumar K, Palanisamy M, Prabaharan V, Ravi R, EzakialNapolean R and Chandrahasan C, 2009. Dystocia due to fetal ascites in a grade murrah buffalo: A case report. Journal of Veterinary and Animal Science 40: 56-57.

[12] Sloss V and. Dufty, JH, 1980. In Sloss, V. and J.H. Dufty (eds) Handbook of Bovine Obstetrics. Williams and Wilkins, Baltimore, U.S.A. Obstetrical pathology, p. 105-111.

[13] Smith, H.A., Jones T.C. and Hunt, R.D. 1996. Veterinary Pathology, pp. 1114-1115.

[14] Thomas, J.O., Cox, A.J. and De Eds, F. 1957. Kidney cysts produced by diphenylamine. Stanford MedicalBulletin, 15:90-93. 


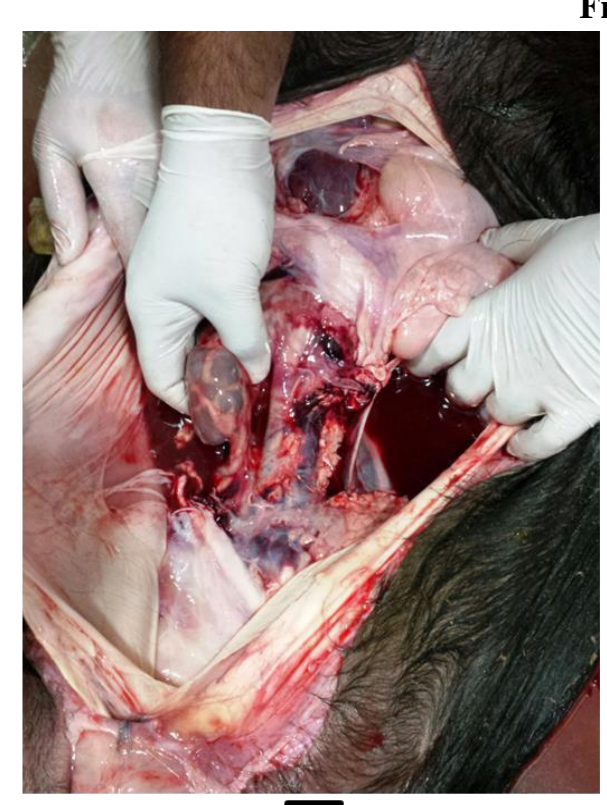

a

\section{Figure}

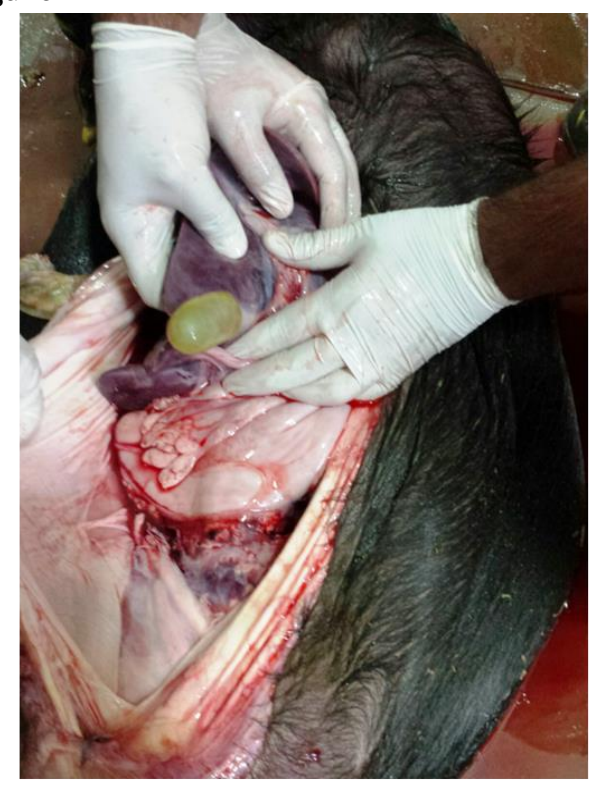

$\mathrm{b}$

Fig 1 Abnormal pathological changes in kidney and liver of fetus. $(a, b)$ 